\title{
INDIAN JOURNAL OF SCIENCE AND TECHNOLOGY
}

\section{RESEARCH ARTICLE}

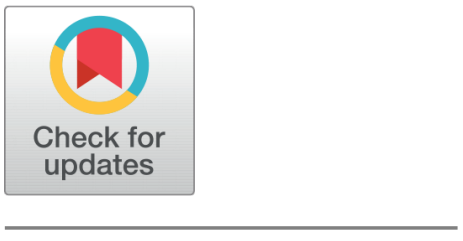

OPEN ACCESS

Received: 29-07-2020

Accepted: 11-09-2020

Published: 29-09-2020

Editor: Dr. Natarajan Gajendran

Citation: Rani PS, Padma R, Prasad RS, Kumar PR (2020) Enhancement of power quality in grid connected PV system. Indian Journal of Science and Technology 13(35): 3630-3641. https://doi.org/ 10.17485/IJST/v13i35.1266

* Corresponding author.

Tel: 9959108386

sobhareveru@gmail.com

Funding: None

Competing Interests: None

Copyright: (c) 2020 Rani et al. This is an open access article distributed under the terms of the Creative Commons Attribution License, which permits unrestricted use, distribution, and reproduction in any medium, provided the original author and source are credited.

Published By Indian Society for Education and Environment (iSee)

ISSN

Print: 0974-6846

Electronic: 0974-5645

\section{Enhancement of power quality in grid connected PV system}

\author{
P Sobha Rani ${ }^{1 *}$, R Padma ${ }^{2}$, R Sarveswara Prasad ${ }^{3}$, P Rathnakar Kumar4 \\ 1 Professor, Department of EEE, Lakireddy Bali Reddy college of Engineering, Mylavaram, \\ 521230, India. Tel.: 9959108386 \\ 2 Assistant Professor, Department of EEE, Lakireddy Bali Reddy college of Engineering, \\ Mylavaram, 521230, India \\ 3 Associate Professor, Department of EIE, Lakireddy Bali Reddy college of Engineering, \\ Mylavaram, 521230, India \\ 4 Assistant Professor, Department of EEE, Lakireddy Bali Reddy college of Engineering \\ 521230, Mylavaram, India
}

\section{Abstract}

Background/Objectives: In grid connected photo voltaic systems inverter is the key element. The inverter is required to shape dc current into sinusoidal current and provide fast response under various disturbances. The quality of power injected into the grid depends on proper inverter control. The objective of this paper is reducing harmonics and to improve power factor in grid connected system with balanced and unbalanced loads. Methods/Statistical analysis: In this study, three control mechanisms, adaptive neuro fuzzy inference system (ANFIS), ANFIS with static synchronous compensator (STATCOM), ANFIS with dynamic voltage restorer (DVR) are employed to improve power quality. The performances of fuzzy and ANFIS controllers are compared in terms of total harmonic distortion and power factor. MATLAB/ Simulink is used to perform the simulation. Findings: ANFIS controller is more effective compared to fuzzy controller. ANFIS controller with DVR gives less THD and improved power factor as compared to fuzzy controller. Novelty/Applications: Fuzzy and neural network controllers do not need any mathematical modelling and give accurate control as compared to classical PI controllers. In this work, ANFIS controller alone and ANFIS controller along with custom power devices STATCOM and DVR are designed for reduction in total harmonic distortion and improved power factor. The results are tabulated, analyzed and compared with fuzzy controller. It has been shown that ANFIS controller gives better performance compared to fuzzy controller.

Keywords: Artificial neural networks (ANN); Adaptive neuro fuzzy inference system (ANFIS); fuzzy controller; power factor; power quality; Total Harmonic Distortion (THD)

\section{Introduction}

It is estimated that renewable energy accounts for $55 \%$ of total installed capacity by 2030 in India. It is planned to increase the capacity of renewable energy to $500 \mathrm{GW}$ by 2030 . 
These sources can be used as standalone or grid connected systems. Nearly all renewable energy systems are grid connected systems. Battery backup is not required in such type of systems. The objective of grid connected system is to generate quality power with feasible cost. Inverter is the key element in such type of systems ${ }^{(1)}$. The harmonics produced in inverter can cause distortion in current waveform which results in low grid power factor and high total harmonic distortion. With advent of technological development in power electronics and by proper control methods of inverter it is possible to get high energy conversion with high power factor and low harmonic distortion.

Classical and advanced control techniques are discussed in literature. P, PD, PI controllers are classical controllers which are simple in structure. The advantage of these controllers is their ability to tune according to requirement. But the drawback of these controllers is their inability to maintain stable error. Proportional resonant (PR) controllers are combination of proportional and resonant controllers. Though these controllers are better than PI controllers, they need accurate tuning and are sensitive to frequency variations. Hysteresis controllers have been used since long time. They do not require any modulator and the hysteresis band can be adjusted to reduce the error. But, these controllers are not appropriate for higher power applications. Sliding mode controllers have the ability to reduce stable errors but a suitable sliding surface is needed and has the limitation of sampling rate. H-infinity controllers, $\mu$-synthesis controllers can be used but, they require high computational procedure. In present days, intelligent controllers, fuzzy and ANN have become preference for researchers due to their fast response time, fast corrective action and satisfactory performance. These controllers do not require any mathematical modeling ${ }^{(2)}$. Fuzzy controller uses linguistic variables. Based on expert knowledge the linguistic strategy is converted to automatic control strategy. But, knowledge of human operator and expertise is required to frame the rule base of fuzzy inference system ${ }^{(3)}$. ANN has a network of trained neurons which are able to perform a specific function by adjusting the weight value. Back propagation algorithm is used to train the neurons. The cluster of neurons has the ability of learning and adoption.

Custom power devices STATCOM, DVR are used to improve power quality at grid side. Fuzzy controlled STATCOM and DVR are proposed in literature ${ }^{(4-7)}$. Whale optimization algorithm is implemented to design PI controller parameters of photovoltaic power systems under different operating conditions ${ }^{(8)}$. Fuzzy and ANN based controllers are proposed in literature to improve the performance of grid connected system ${ }^{(9-11)}$. PI, fuzzy based FACTS devices for grid connected system is designed for control of real and reactive power flow in grid connected system ${ }^{(12)}$. To mitigate harmonics and to control voltage fluctuations a dynamic voltage regulator and its controller are designed ${ }^{(13)}$.

So far, ANFIS Controlled STATCOM and DVR are not used for power quality enhancement in grid connected PV System. Hence, novel ANFIS controller is proposed in this paper to reduce harmonic distortion. ANFIS controller is an efficient controller and combines the advantages of both fuzzy and ANN. It has neural network architecture combined with fuzzy reasoning. With ANFIS controller, right rule base can be achieved by selecting proper membership functions. In this paper, a comparison is made between fuzzy and ANFIS controller based STATCOM and DVR. It is found that this novel technique improves power factor and reduces harmonic distortion when compared to fuzzy controller based system.

\section{Proposed System}

The solar PV power circuit comprises of PV array, DC-DC converter, DC-AC inverter, grid filter, grid and load. The PV array considered in this paper produces a power of $85.2 \mathrm{KW}$ at a solar radiation of $1000 \mathrm{~W} / \mathrm{m}^{2}$. The characteristics of PV array are presented in Table 1 (NREL System Advisor Model (Jan. 2014).

Table 1.

\begin{tabular}{ll}
\hline PV module type & 1Soltech 1STH-215P \\
\hline No.of Parallel strings in Array & 40 \\
No. of series connected modules per string & 10 \\
max.power for module & $213.15 \mathrm{~W}$ \\
Short circuit current & $7.84 \mathrm{~A}$ \\
Open circuit voltage & $36.3 \mathrm{~V}$ \\
\hline
\end{tabular}

In grid connected PV system, the main objective is to obtain quality power without any harmonics at grid. The PV system with controllers to obtain optimal performance is shown in Figure 1. 


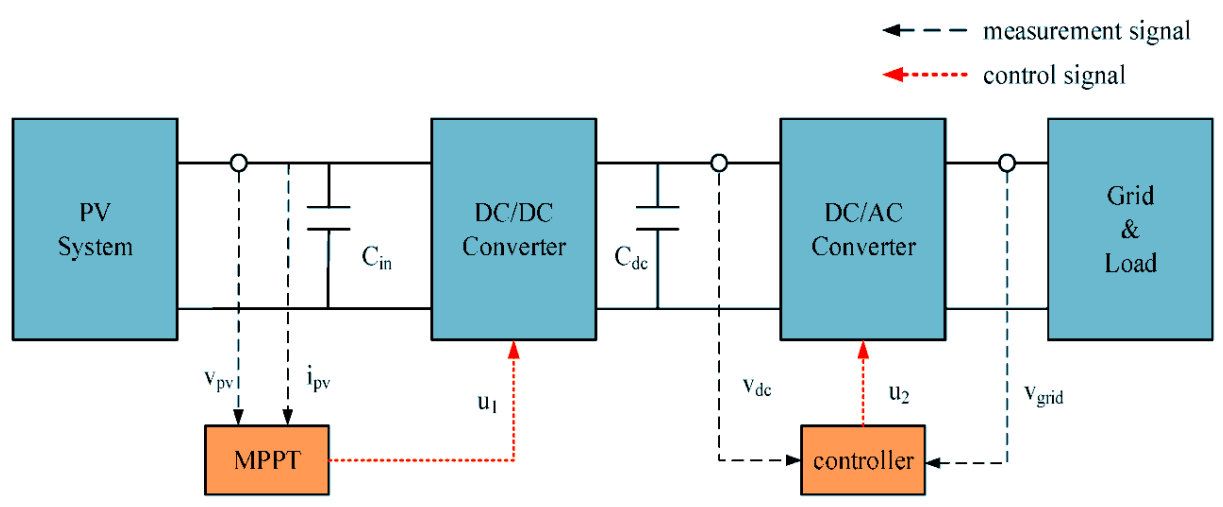

Fig 1. Block diagram of Solar PV system controllers

The control mechanism is divided into two parts: (i) MPPT controller to extract maximum power from PV array. (ii) Controller on inverter side to control the duty cycle in inverter.

(i)The efficiency of power transfer from PV system depends on the availability of sunlight on solar modules and the electrical characteristics of load. Since the availability of sunlight is not constant, the maximum power transfer efficiency also changes. Maximum power point tracking (MPPT) is the process of choosing the optimal load to be presented to PV modules to get the maximum power output. There are number of methods available in literature to get MPPT. In this paper, Perturb and Observe $(\mathrm{P} \& \mathrm{O})$ method is implemented to get MPPT. In this method, the controller fine- tunes the voltage to get maximum power.

(ii) Inverter control mechanism ensures control of the total harmonic distortion of current injected to meet grid requirements. In view of nonlinear nature of grid PV systems, artificial Intelligence techniques are suitable to design the inverter control system. The inverter control structure comprises of two control loops. One control loop is provided by STATCOM as current regulator. Second control loop is DVR in voltage regulator.

\section{Proposed Controllers}

\subsection{Fuzzy Controller}

The fuzzy logic controller involves three stages: fuzzification, inference mechanism and defuzzification. In fuzzification process the input data is converted into fuzzy membership function. The fuzzy data values are between 0 and 1 . Fuzzy rules are framed in Inference mechanism to get the optimal output ${ }^{(14)}$. In defuzzification, the fuzzy data is converted into real life data. The error between reference voltage and measured voltage and its derivative are input to fuzzy controller as shown in Figure 2.

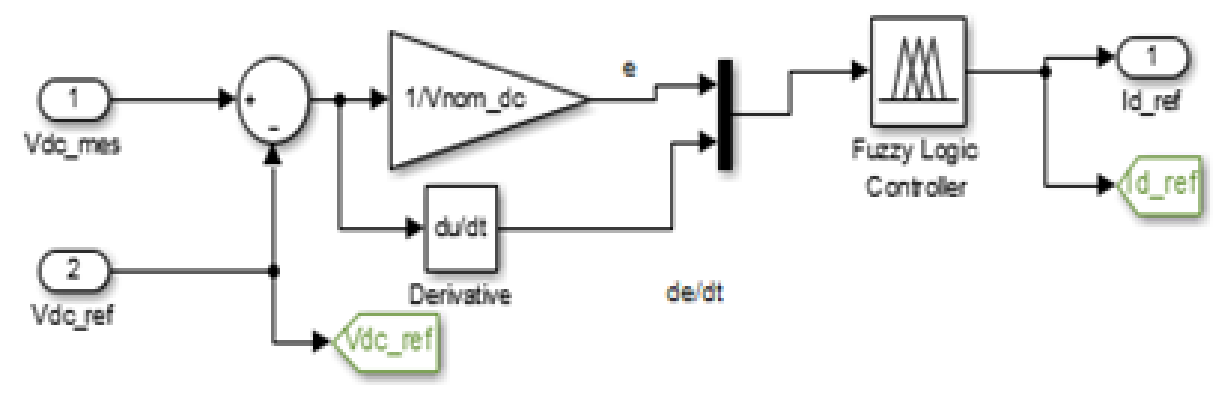

Fig 2. Fuzzy controller in inverter side of solar PV system

Figures 3 and 4 represents membership function and rule viewer. Triangular membership function is chosen as membership function of fuzzy subset. The rules framed for rule execution are presented in Table 2. 


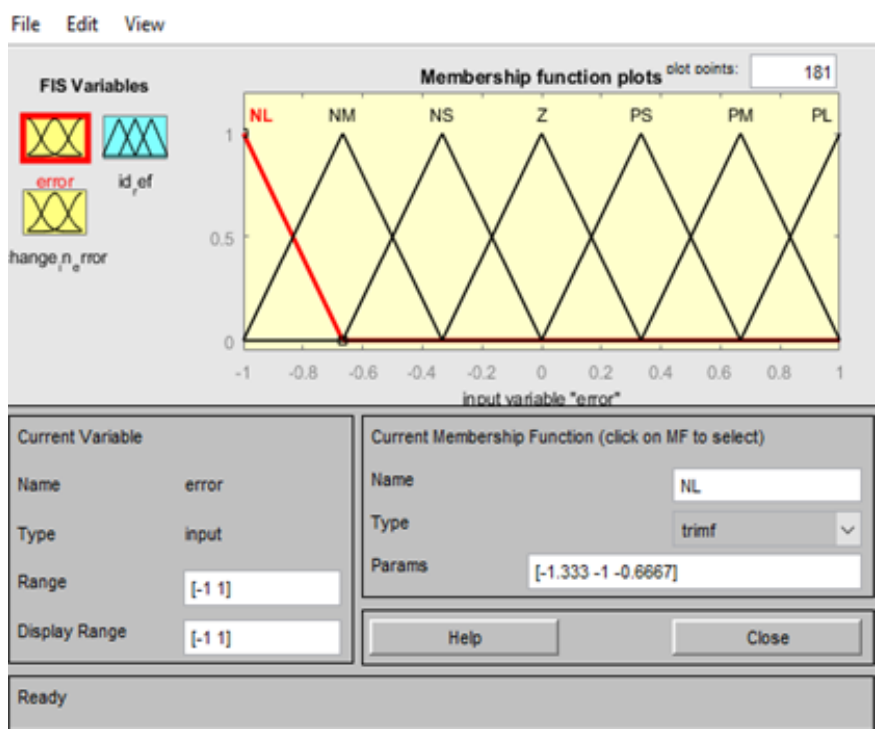

Fig 3. Membership Function: Fuzzy Editor

Table 2. Rules for Fuzzy Logic Controller

\begin{tabular}{|c|c|c|c|c|c|c|c|}
\hline $\begin{array}{c}\text { e } \\
\text { deddt }\end{array}$ & L_NE & M_NE & S_NE & ZE & S_PO & M_PO & L_PO \\
\hline L_NE & L_NE & L_NE & L_NE & L_NE & M_NE & S_NE & ZE \\
\hline M_NE & L_NE & M_NE & S_NE & ZE & S_PO & L_NE & M_NE \\
\hline S_NE & M_NE & S_NE & S_NE & S_PO & M_PO & L_NE & M_NE \\
\hline ZE & S_NE & ZE & S_PO & M_PO & L_PO & L_NE & S_NE \\
\hline L_PO & ZE & S_PO & M_PO & L_PO & L_PO & S_NE & ZE \\
\hline M_PO & L_PO & M_PO & L_PO & L_PO & L_PO & ZE & S_PO \\
\hline S_PO & M_PO & L_PO & L_PO & L_PO & L_PO & L_NE & L_NE \\
\hline
\end{tabular}

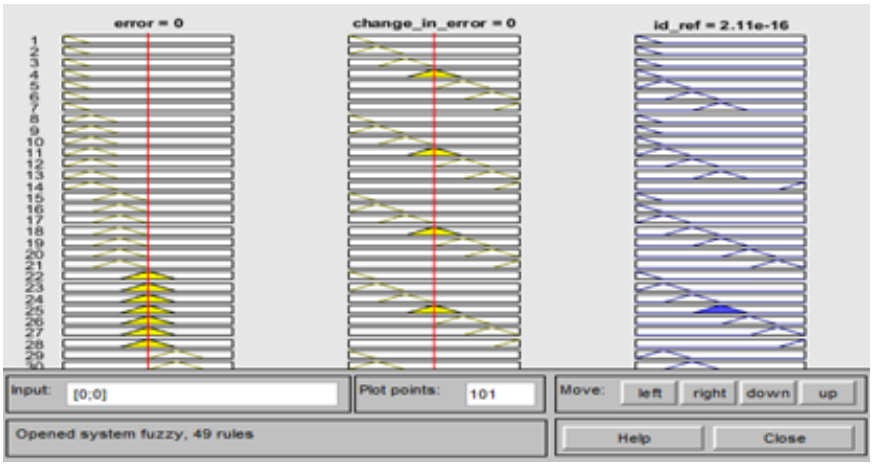

Fig 4. Rule Viewer: Fuzzy 


\subsection{ANFIS Controller}

As compared to conventional controllers, intelligent controllers such as fuzzy logic and neural networks present a good estimation of parameter variations. In this controller, neural network techniques are used to select appropriate rule box. Figure 5 represents ANFIS architecture. It consists of five layers.

Fuzzification layer: Determines membership functions relating to input values.

Rule layer : Generates firing strengths for the rules

Normalization layer: Determines the activation level of each fuzzy rule.

Defuzzification layer: Generates defuzzified values

Summation neuron layer: Returns the final output.

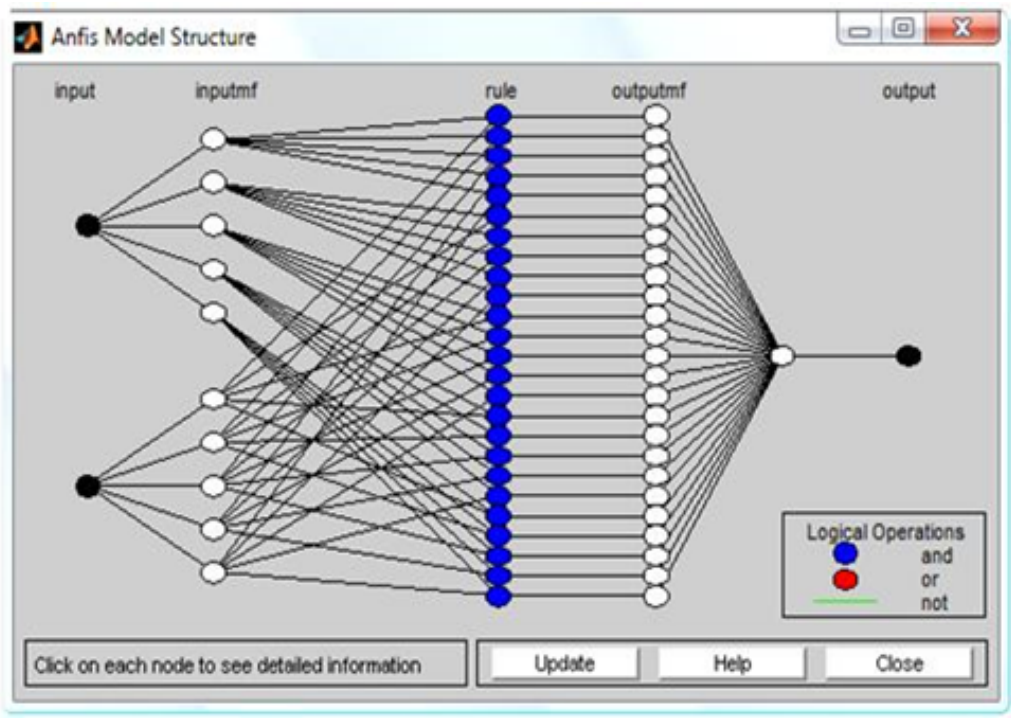

Fig 5. ANFIS model with ANN architecture showing input, output and hidden layers

The inputs to the controller are error and change in error. The block diagram of ANFIS controller is shown in Figure 6 . Fuzzification block converts crisp values into linguistic variables which become input to rule base block. Rules are framed in rule base block. The rule based block is connected to ANN block. Optimal rules are fired and the defuzzified output is used to form firing pulses to control inverter.

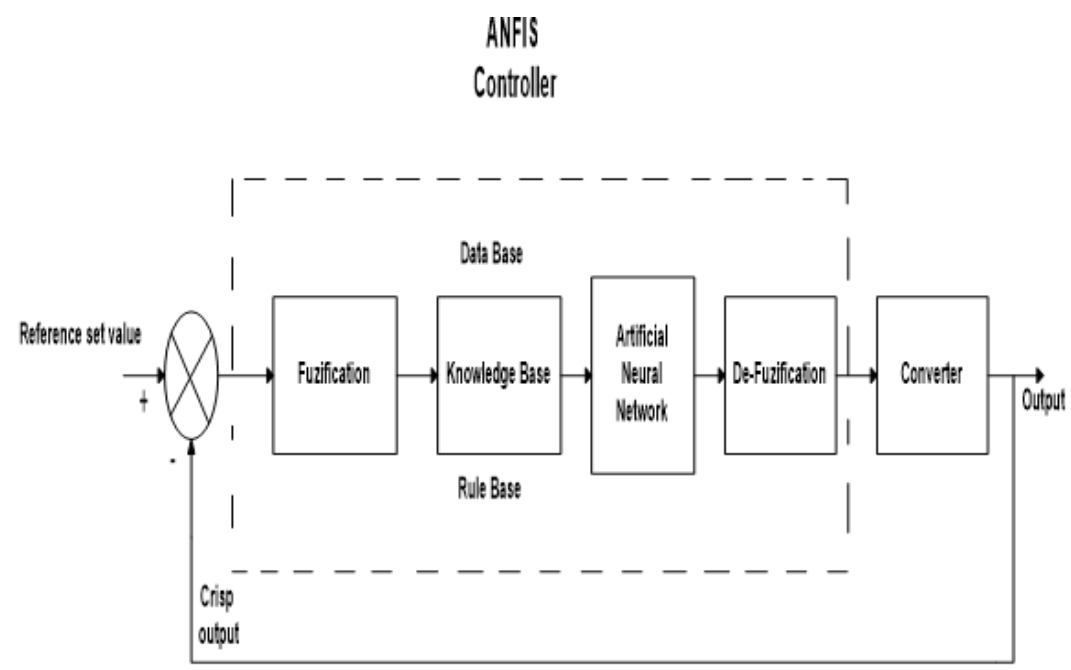

Fig 6. Block Diagram of ANFIS controller 


\subsection{STATCOM}

Static synchronous compensator (STATCOM) is a shunt device which can be used for reducing the effect of harmonics in load current and for limiting reactive power fluctuations. In some cases, it can mitigate voltage sags. The basic structure of STATCOM consists of three-phase voltage source converter, a dc capacitor and a coupling transformer. It is connected to grid through coupling transformer. The reactive power exchange to grid is achieved by injecting current in quadrature with voltage. ANFIS controller in current regulator loop of STATCOM is shown in Figure 7. Two current components of STATCOM $\mathrm{I}_{d}$ and $\mathrm{I}_{q}$ are compared with reference values. The error and derivative of error are sent as inputs to ANFIS controller.

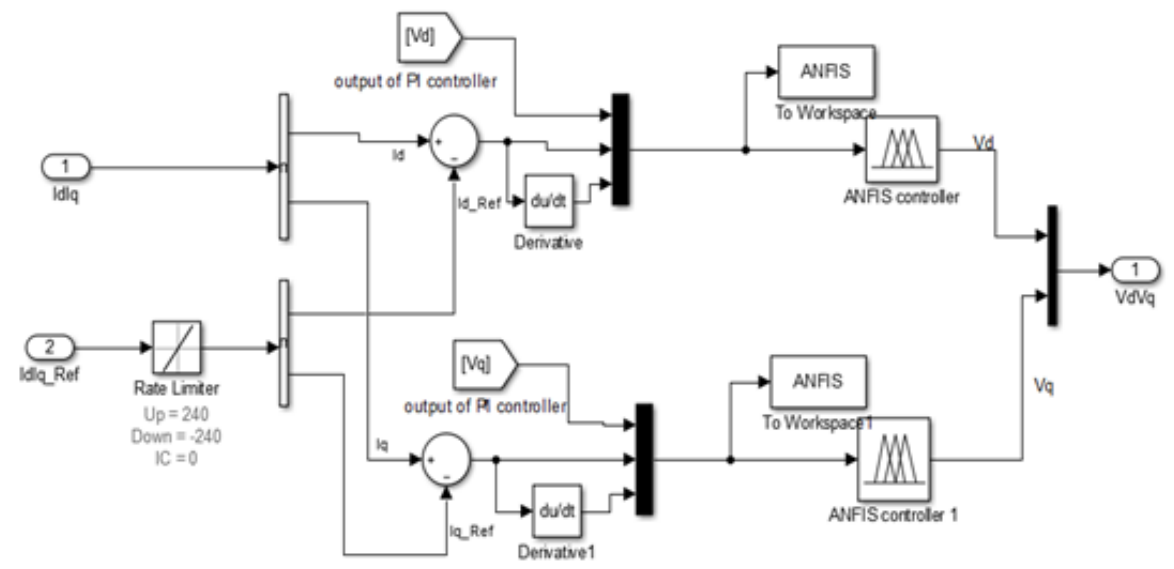

Fig 7. ANFIS controller in current regulator loop of STATCOM

\subsection{DVR}

Dynamic voltage restorer is a series compensation device which injects voltage in series and in synchronism with system voltage. It can absorb or generate real and reactive power independently at load side. The main application of DVR is voltage sag/swell mitigation, compensation of series voltage harmonics and reduction of transients. To overcome voltage related problems, DVR is the most economical solution. The general structure of DVR consists of voltage source converter, injection transformer, energy storage device and a control system. The ANFIS controller block in voltage regulator loop of DVR is shown in Figure 8. Dynamic voltage restorer injects the voltage needed to balance the load voltage from any disturbance. Here, the controller inputs are an error signal obtained from difference between reference voltage and injected voltage and the derivative of error signal.

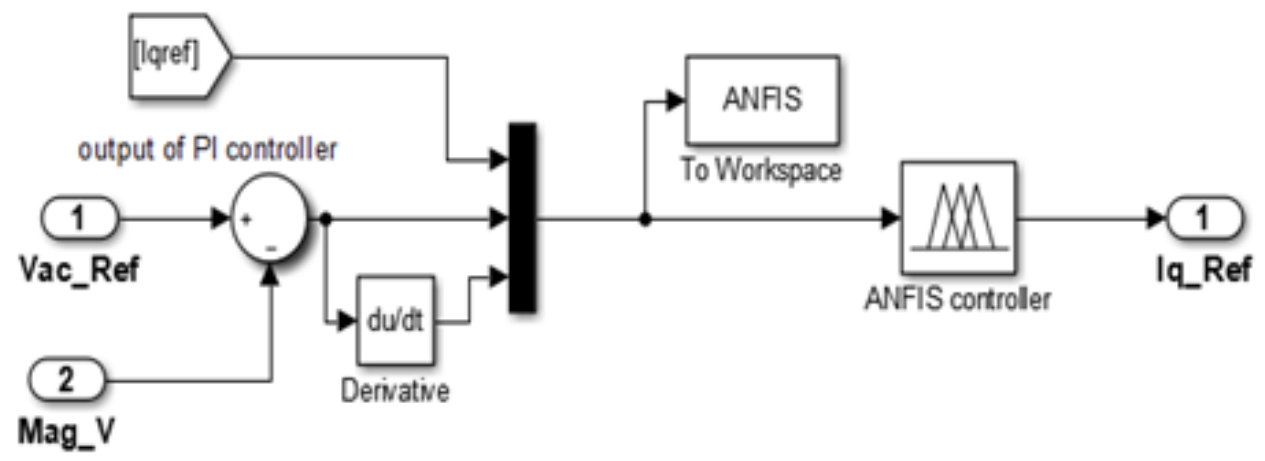

Fig 8. ANFIS controller in Voltage regulator loop of DVR 


\section{Simulation and results}

Grid connected PV system with balanced and unbalanced load is considered in this paper. The proposed ANFIS controller structure for grid connected PV system to reduce harmonics is shown in Figure 9. This controller comprises of two input neurons, one output neuron and four hidden layers. The two input neurons i.e. error and change in error are presented as inputs to first hidden layer i.e. input membership function of ANN block. In second and third hidden layers (rule base and membership function) a set of 49 rules are framed by training and optimal rules are selected and made available at fourth hidden layer (output). The optimal rules are fired here and the resulting defuzzified output is the output neuron. This output is utilized to initiate the firing pulses applied to Inverter Bridge to control inverter current.

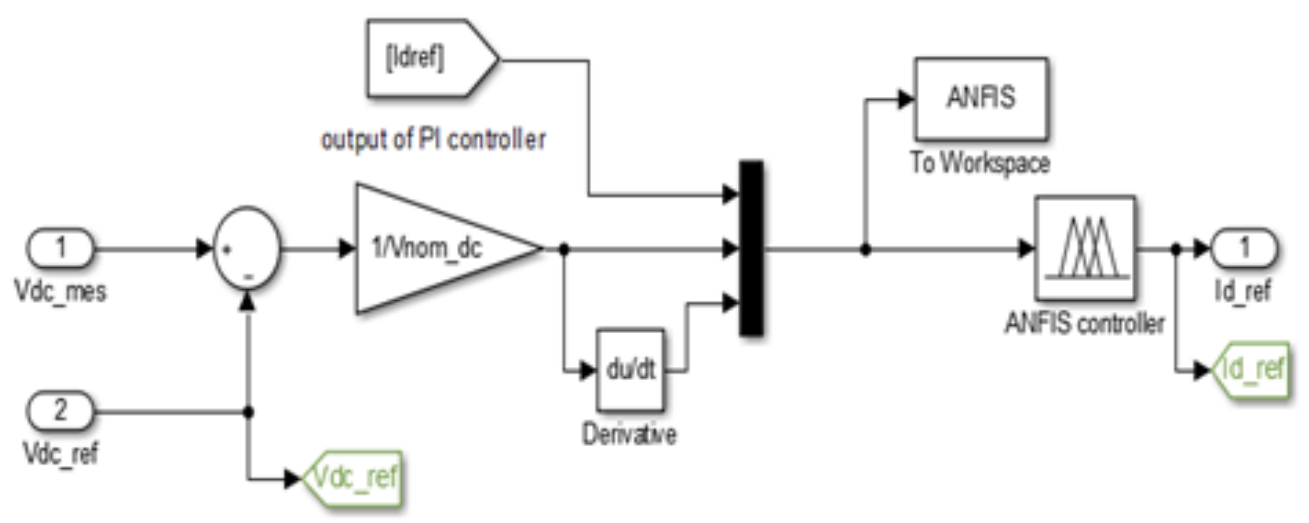

Fig 9. ANFIS controller block in inverter side of solar PV system 
Simulation diagram of ANFIS controller is presented in Figure 10. Its THD analysis is shown in Figure 11. The THD is found to be $0.57 \%$.

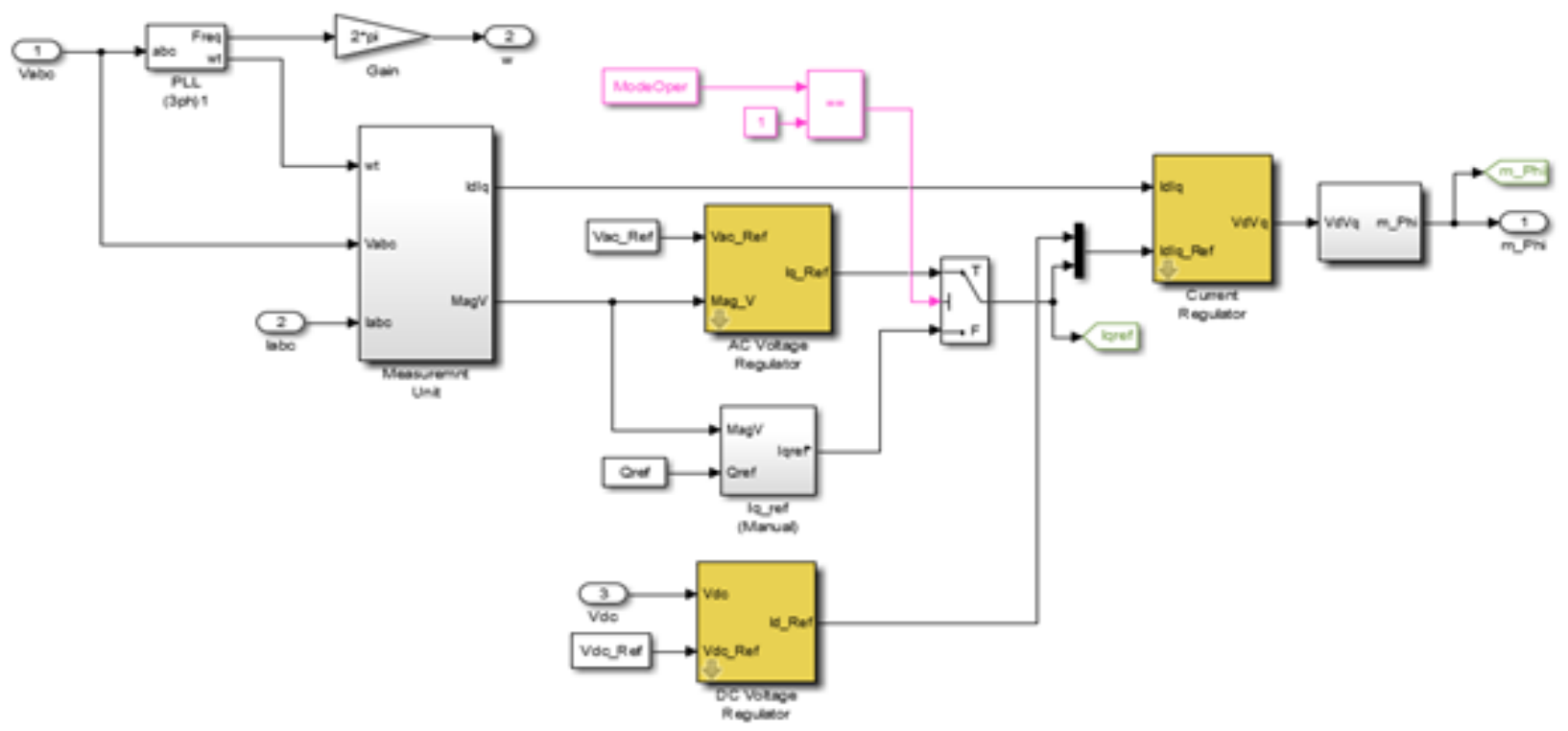

Fig 10. Simulation diagram of ANFIS controller

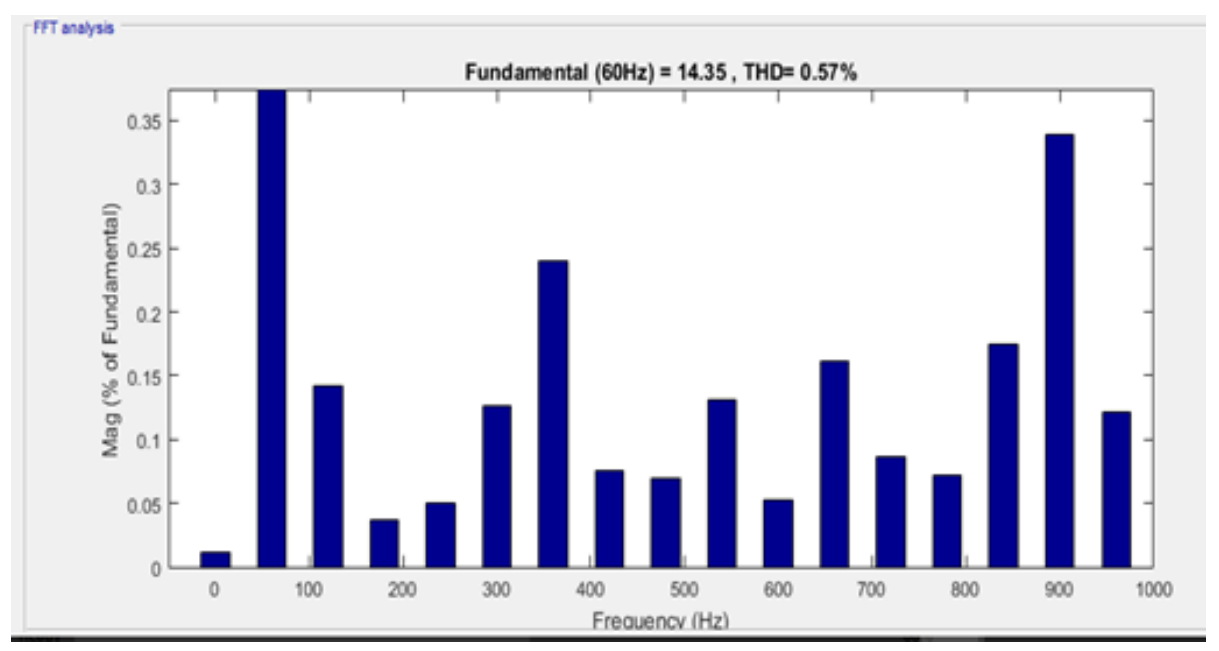

Fig 11. THD analysis of ANFIS controller

STATCOM can be used to reduce the harmonic content in load current and thereby regulating voltage of distribution/transmission lines. In the proposed system, ANFIS controller is used in current regulator block of STATCOM. Current regulator regulates the error between desired current and actual current. The simulation diagram is shown in Figure 12. Its THD analysis with fuzzy and ANFIS controllers are presented in Figures 13 and 14. THD obtained with fuzzy controller is $1.33 \%$ and with ANFIS controller is $0.48 \%$.

DVRs inject the appropriate voltage to keep the load voltage constant and balanced if any anomaly occurs in supply voltage. In the proposed system, ANFIS controller is employed in voltage regulator loop of DVR as shown in Figure 15. The controller inputs are error and change in error. An error signal is attained from reference voltage and injected voltage value. THD analysis with fuzzy controller is depicted in Figure 16.THD obtained with fuzzy controller is $1.03 \%$ and with ANFIS controller is $0.36 \%$. 


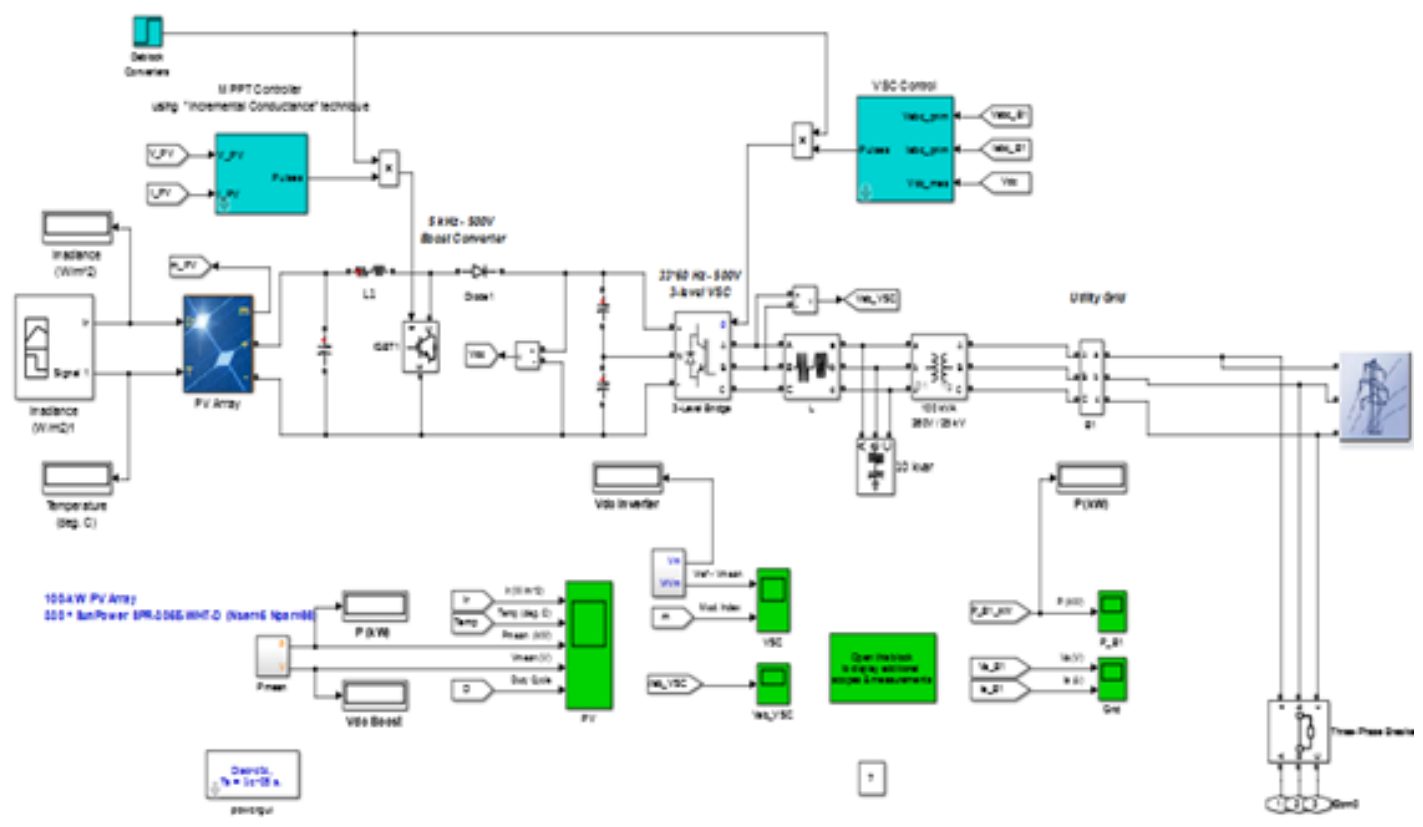

Fig 12. Simulation diagram of ANFIS controller in STATCOM current loop

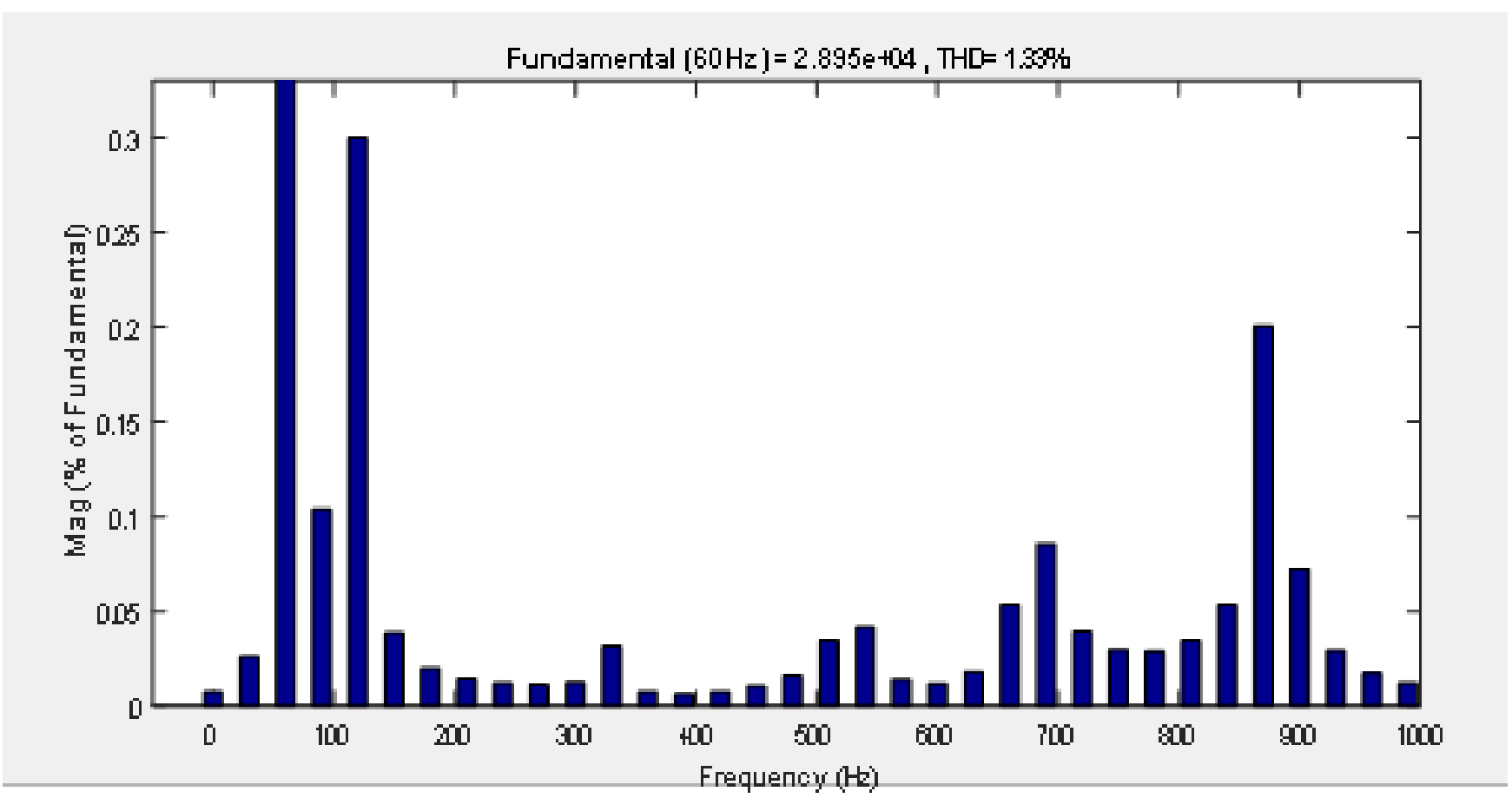

Fig 13. THD analysis of STATCOM with Fuzzy controller 


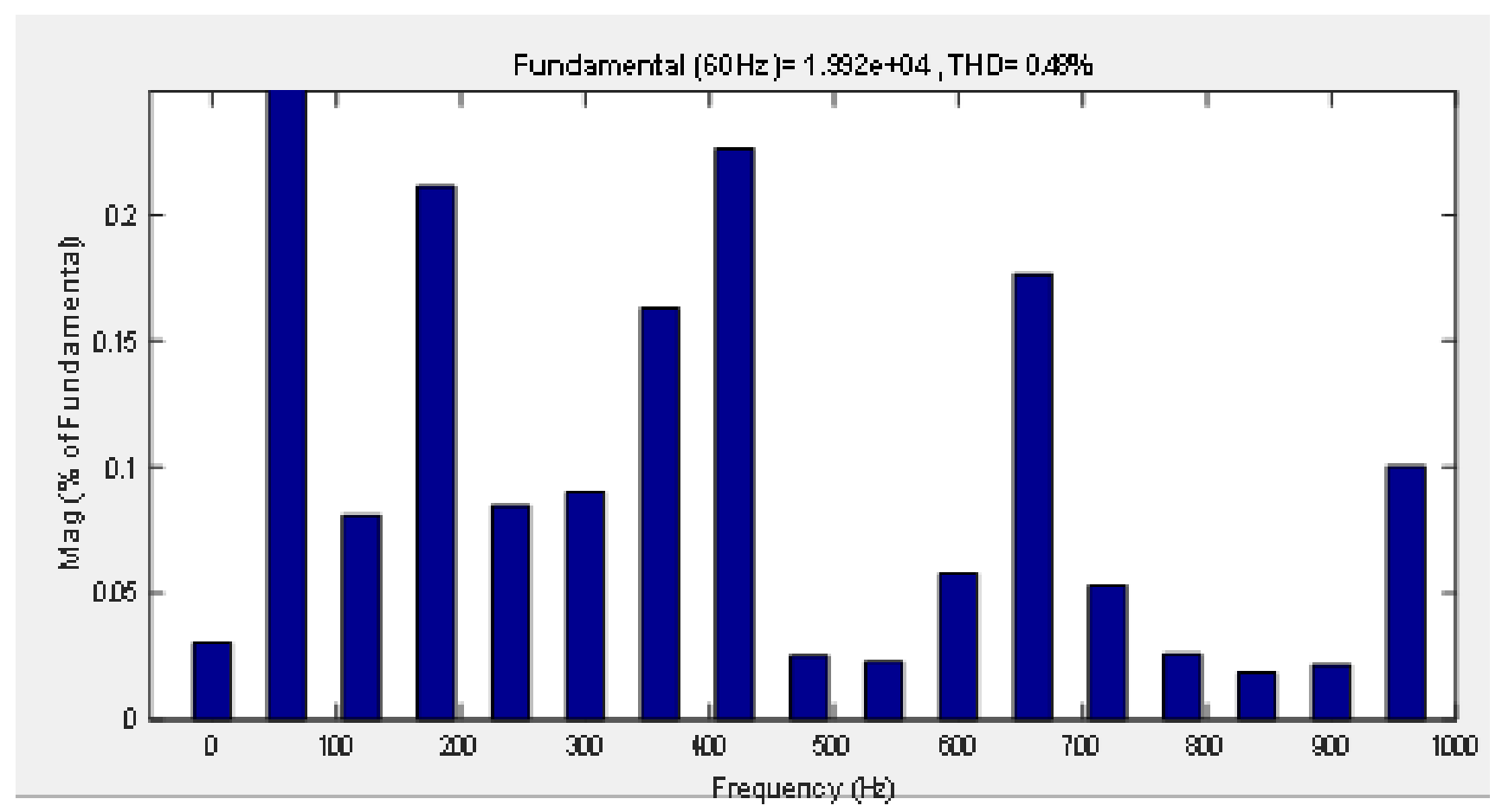

Fig 14. THD analysis of STATCOM with ANFIS controller

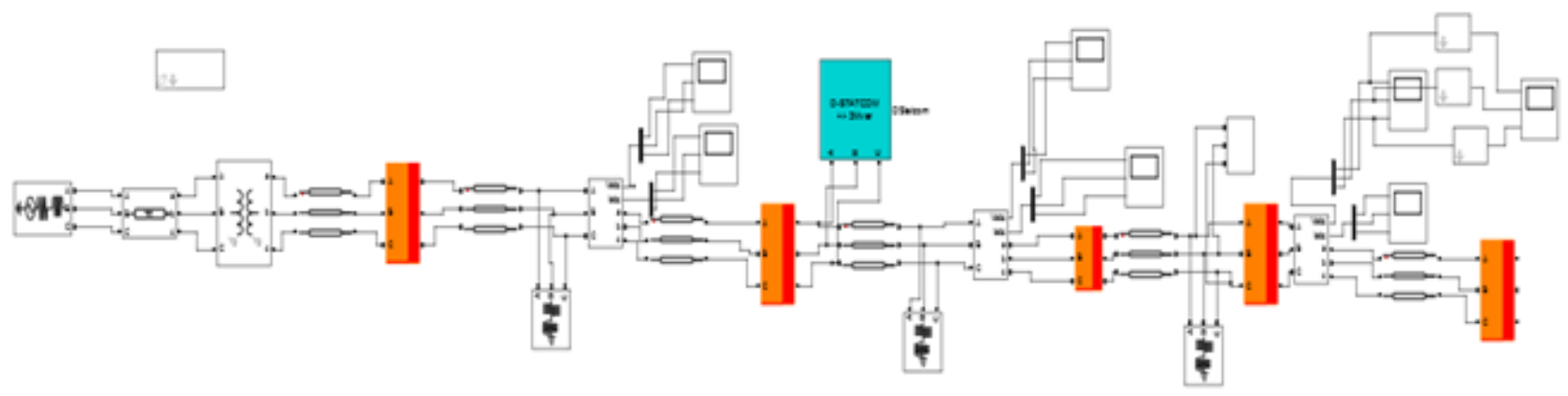

Fig 15. Simulation diagram of DVR in voltage regulator loop of ANFIS 


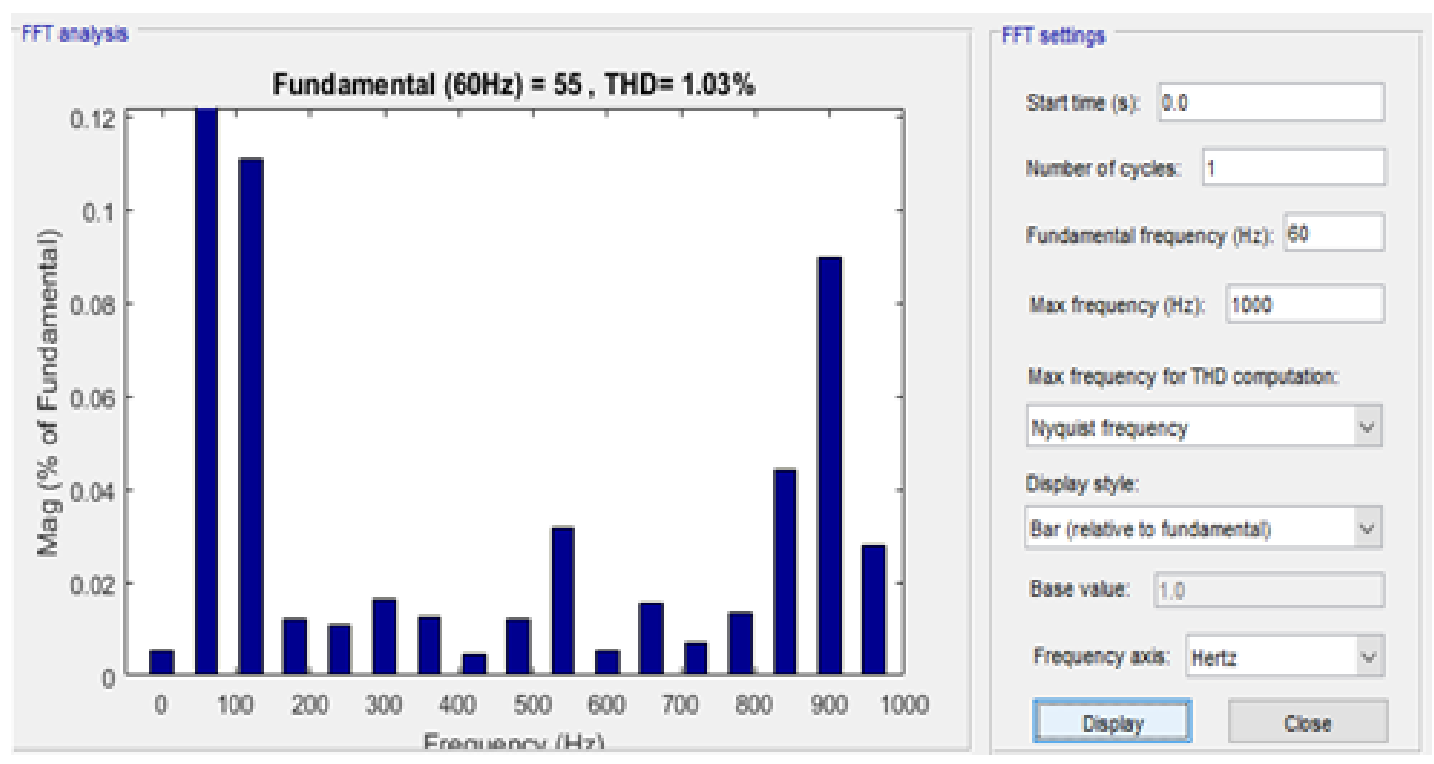

Fig 16. THD analysis of DVR with fuzzy controller

THD and power factor values for balanced and unbalanced loads with fuzzy and ANFIS controllers are compared for three cases (i) controller alone (ii) fuzzy/ANFIS controller with STATCOM (iii) fuzzy/ANFIS controller with DVR and the results are tabulated in Table 3. It can be seen that ANFIS controller with DVR gives best result.

Table 3. Comparison of THD and p.f with fuzzy and ANFIS controllers

\begin{tabular}{|c|c|c|c|c|c|}
\hline \multirow{2}{*}{ Load type } & & \multicolumn{2}{|c|}{ Fuzzy controller } & \multicolumn{2}{|c|}{ ANFIS controller } \\
\hline & & THD & p.f & THD & p.f \\
\hline \multirow{3}{*}{ Balanced load } & & 1.31 & 0.85 & 0.81 & 0.87 \\
\hline & With STATCOM & 1.48 & 0.86 & 1.33 & 0.89 \\
\hline & With DVR & 1.19 & 0.95 & 0.87 & 0.97 \\
\hline \multirow{3}{*}{ Unbalanced load } & & 1.27 & 0.83 & 0.57 & 0.85 \\
\hline & With STATCOM & 1.33 & 0.86 & 0.48 & 0.90 \\
\hline & With DVR & 1.03 & 0.87 & 0.36 & 0.99 \\
\hline
\end{tabular}

\section{Conclusion}

In this work, Inverter control using ANFIS controller along with STATCOM and DVR is implemented for power quality improvement in grid connected PV system with balanced and unbalanced loads. The obtained results are compared to fuzzy controller. Adaptive Neuro Fuzzy Inference system provides better control over fuzzy control. The proposed controller in inverter improves the power quality. It has been found that ANFIS controller with DVR gives less THD and improved power factor as compared to fuzzy controller.

\section{References}

1) Afroze S, Udaykumar RY, Naik A. A systematic approach to grid connected PV system. In: IEEE Fifth Power India Conference. 2012;p. 1-5. Available from: https://doi.org/10.1109/PowerI.2012.6479486.

2) Tahir S, Wang J, Baloch MH, Kaloi GS. Digital control techniques based on voltage source inverters in renewable energy applications- A review. Electronics. 2018;7. Available from: a.https://www.researchgate.net/deref/http\%3A//dx.doi.org/10.3390/electronics7020018.

3) Suresh M, Panda AK, Suresh Y. Fuzzy Controller Based 3Phase 4Wire Shunt Active Filter for Mitigation of Current Harmonics with Combined p-q and Id-Iq Control Strategies. Energy and Power Engineering. 2011;03(01):43-52. Available from: https://dx.doi.org/10.4236/epe.2011.31007.

4) Ilango K, Bhargav A, Trivikram A, Kavya PS, Mounika G, Nair MG. Power quality improvement using STATCOM with renewable energy sources. In: IEEE 5th India International Conference on Power Electronics (IICPE). 2012;p. 1-6. Available from: https://ieeexplore.ieee.org/document/6450462. 
5) Farhadi-Kangarlu M, Babaei E, Blaabjerg F. A comprehensive review of dynamic voltage restorers. International Journal of Electrical Power \& Energy Systems. 2017;92:136-155. Available from: https://dx.doi.org/10.1016/j.ijepes.2017.04.013.

6) Coteli R, Dandil B, Fekrit A. Fuzzy-PI current controlled DSTATCOM. Gaji university journal of science. 2011;24(1):92-99. Available from: https: //www.researchgate.net/publication/289804840.

7) Shi J, Noshadi A, Kalam A, Shi P. Fuzzy logic control of DSTATCOM for improving power quality and dynamic performance. In: Australasian Universities Power Engineering Conference (AUPEC). 2015;p. 1-6. Available from: https://ieeexplore.ieee.org/document/7324796.

8) Hasanien HM. Performance improvement of photovoltaic power systems using an optimal control strategy based on whale optimization algorithm. Electric Power Systems Research. 2018;157:168-176. Available from: https://dx.doi.org/10.1016/j.epsr.2017.12.019.

9) Zheng Z, Zhang T, Xue J. Application of Fuzzy Control in a Photovoltaic Grid-Connected Inverter. Journal of Electrical and Computer Engineering. 2018;2018:1-10. Available from: https://dx.doi.org/10.1155/2018/3806372.

10) Sulehri AM. Power quality improvement in an AC network using artificial neural network and hysteresis band current controller. Ingeniería e Investigación. 2018;38(3):42-49. Available from: https://dx.doi.org/10.15446/ing.investig.v38n3.67885.

11) Agrawal S, Palwalia DK, Kumar M. Performance Analysis of ANN Based three-phase four-wire Shunt Active Power Filter for Harmonic Mitigation under Distorted Supply Voltage Conditions. IETE Journal of Research. 2019;2019:1-9. Available from: https://dx.doi.org/10.1080/03772063.2019.1617198.

12) Thumu R. PI, Fuzzy Based Controllers for FACTS Devices in Grid Connected PV system. International Journal of Integrated Engineering. 2019;11(6):176185. Available from: https://publisher.uthm.edu.my/ojs/index.php/ijie/article/view/2954.

13) Al-Shetwi QA, Hannan MA, Jern KP, Alkahtani AA, Abas AEP. Power Quality Assessment of Grid-Connected PV System in Compliance with the Recent Integration Requirements. Electronics. 2020;9(2):366-366. Available from: https://dx.doi.org/10.3390/electronics9020366.

14) Padma R, Rani P, Prasad R. Power quality enhancement in grid PV system using fuzzy controller. International journal of advanced science and Technology. 2020;29(4):994-1002. Available from: http://sersc.org/journals/index.php/IJAST/article/view/4769. 